\title{
Nickel catalytic graphitized porous carbon as electrode material for high
}

\section{performance supercapacitors}

\author{
Keliang Wang ${ }^{\mathrm{a}}$, Yuhe $\mathrm{Cao}^{\mathrm{a}}$, Xiaomin Wang ${ }^{\mathrm{a}}$, Parashu Ram Kharel ${ }^{\mathrm{c}}$, William Gibbons ${ }^{\mathrm{d}}$, Bing \\ Luo $^{\mathrm{e}}$, Zhengrong Gu ${ }^{1, *}$, Qihua Fan ${ }^{2, *}$, Lloyd, Metzger ${ }^{\mathrm{f}}$ \\ a Agricultural and Biosystems Engineering Department, South Dakota State University, Brookings, SD 57007, United States \\ b Electrical Engineering and Computer Science Department, South Dakota State University, Brookings, SD 57007, United States \\ c Physics Department, South Dakota State University, Brookings, SD 57007, United States \\ d Biology and Microbiology Department, South Dakota State University, Brookings, SD 57007, United States \\ e Characterization Facility of the University of Minnesota, Minneapolis, MN 55455, United States \\ f Dairy Science Department, South Dakota State University, Brookings, SD 57007, United States
}

\section{Abstract:}

Whey-protein-derived nitrogen-doped porous carbon has been prepared by preliminary carbonization at $400{ }^{\circ} \mathrm{C}$ and final $\mathrm{KOH}$ activation at $700{ }^{\circ} \mathrm{C}$ combined with catalytic graphitization. Physical characterization indicated that the nitrogen-doped activated electrode material had a large specific surface area $\left(2536 \mathrm{~m}^{2} \mathrm{~g}^{-1}\right)$ and plenty of interconnected cavities, which greatly improved the performance of supercapacitors. Electrochemical measurements demonstrated that the as-prepared activated electrode material had exceptionally high capacitance of $248 \mathrm{~F} \mathrm{~g} \mathrm{~g}^{-1}$ at charge/discharge current density of $0.1 \mathrm{~A} \mathrm{~g}^{-1}$. Moreover, the prepared supercapacitors exhibited ideal capacitive behavior with nearly no capacitance loss in 6 mol L $\mathrm{L}^{-1}$ $\mathrm{KOH}$ at different charge/discharge current densities ranging from 0.1 to $5 \mathrm{~A} \mathrm{~g}^{-1}$ after 1,000 charge/discharge cycles. The derived energy density was $12.4 \mathrm{Wh} \mathrm{kg}^{-1}$ at a power density of 495 $\mathrm{W} \mathrm{kg}{ }^{-1}$ under operational conditions. These results suggested that the whey-protein-derived porous carbon is a promising supercapacitor electrode material.

Keywords: nickel catalytic graphitized, nitrogen doped carbon, porous carbon, supercapacitor

\footnotetext{
1 Z R. Gu Tel./fax: + 1605688 5372. Email address: zhengrong.gu@sdstate.edu (Z R. Gu)

${ }^{2}$ Q H. Fan Tel./fax: + 1605 688-5910. Email address: qihua.fan@ sdstate.edu (Q H. Fan)
} 


\section{Introduction}

The increasing demand for high power energy storage devices has attracted significant attention on supercapacitors that feature high power density, long lifetime, and fast charge/discharge [1-3]. Based on their working mechanism, supercapacitors are classified into two major types: pesudocapacitor and electric double-layer capacitors (EDLCs). Pseudocapacitors use rapid reversible redox reactions at the surface of electrode materials and offer high specific capacitance. In pseudocapacitors, metal oxides such as $\mathrm{NiO}, \mathrm{CoO}$ and $\mathrm{MnO}_{2}$ are commonly used as the electrodes [4-6]. In contrast, EDLCs store charge electrostatically by forming a double layer of electrolyte ions on the surface of conductive electrodes. Activated carbon-based materials are the most common electrodes in EDLCs. The desired properties for the carbon electrodes are high electrical conductivity, large specific surface area (SSA) with accessible porosity, and low cost [7-9].

Graphene has a theoretical specific capacitance of about $526 \mathrm{~F} \mathrm{~g}^{-1}$, however, only $25.7 \%$ to $39.0 \%$ of this potential was achieved in experiments [10]. This large discrepancy has stimulated intensive research activities to improve the specific capacitance of carbon-based materials. In 2009, Dai et al. enhanced the performance of carbon based electrocatalysts by introducing nitrogen $(\mathrm{N})$ in carbon-based materials increase electrical conductivity [11]. Inspired by $\mathrm{N}$ introduction effects, varieties of doping methods were developed and applied into EDLCs. One of their approaches to adding nitrogen in carbon-based materials was to use N-rich organic chemicals (pyrrole, aniline, melamine and ethylenediamine) [12-15] to modify the properties of carbon materials, including carbon nanotube (CNT) and graphene. However, these materials were neither eco-friendly nor cost effective. Another strategy to produce $\mathrm{N}$-doped carbon materials was to carbonize the nitrogen containing precursors, such as yogurt, coconut shell, grape seed, distillers dried grains and so forth [16-20]. This approach offered significant advantages in that it did not use toxic chemicals or produce noxious by-products, and had relatively low cost. Nitrogen in the renewable bio-feedstock sources could be easily immobilized in the carbon matrix during heat treatment, which is much easier and safer than carbon coating using nitrogen containing toxic chemicals.

Recently, N-containing biomass as feedstock for $\mathrm{N}$-doped porous carbon materials for high performance EDLCs had attracted great research interest because of the low cost, sustainability 
and accessibility. $\mathrm{N}$-doped porous carbon materials must be subjected to a high degree of graphitization to achieve excellent EDLCs performance. Conventional graphitization required high temperatures of 2,500-3,000 ${ }^{\circ} \mathrm{C}$ [21] and is therefore, energy intensive and inefficient. Alternatively, catalytic graphitization was a more effective method to produce graphitic carbon. In this method, a transition metal ( $\mathrm{Fe}, \mathrm{Co}$, or $\mathrm{Ni}$ ) served as catalyst during pyrolysis process, which led to graphitization temperatures below $1,000{ }^{\circ} \mathrm{C}$ and the potential of low-cost manufacturing [22]. Inspired by the effects of $\mathrm{N}$ doping and catalytic graphitization, the authors studied a whey protein as carbon precursor, in combination with $\mathrm{Ni}\left(\mathrm{NO}_{3}\right)_{2}$ as catalyst precursor to produce high-performance EDLC. Whey protein is a homogeneous, free flowing, semisuperior capacitive performance.

\section{Material and methods}

Synthesis

Preparation of activated carbon: Whey protein $(80 w t \%)$ in the form of a homogeneous, free flowing and semi-hygroscopic powder was obtained from the Dairy Science Department, South Dakota State University. To prepare the activated carbon, whey protein was mixed with nickel nitrate hexahydrate $\left(\mathrm{Ni}\left(\mathrm{NO}_{3}\right)_{2} \bullet 6 \mathrm{H}_{2} \mathrm{O}\right.$, Fisher Scientific) in a mass ratio of $14: 1$. The mixture was then placed into a steel crucible and heated at $400{ }^{\circ} \mathrm{C}$ for an hour in a muffle $(1100$ box furnace, Lindberg/Blue M, Thermo Scientific) under a continuous flow (96 $\mathrm{ml} \mathrm{min}^{-1}$ ) of pure nitrogen gas. After this heat treated material was cooled down, it was mixed with potassium hydroxide ( $\mathrm{KOH}$, Fisher Scientific) in a mass ratio of 1:3. To facilitate the mixing process, $20 \mathrm{~mL}$ deionized water was added to the mixture. The final mixture was first dried at $110{ }^{\circ} \mathrm{C}$ for 24 hours and then transferred into muffle to anneal at $700{ }^{\circ} \mathrm{C}$ for 1 hour under a continuous flow $\left(96 \mathrm{ml} \mathrm{min}^{-1}\right)$ of pure nitrogen gas. These annealed carbon samples were allowed to slowly cool to room temperature and washed with $0.1 \mathrm{~mol} \mathrm{~L}^{-1}$ hydrogen chloride $\left(\mathrm{HCl}\right.$, Fisher Scientific) at $110{ }^{\circ} \mathrm{C}$ for 1 hour in a $60 \mathrm{~mL}$ polytetrafluoroethylene (PTFE) autoclave to remove the residual $\mathrm{KOH}$ and impurities after it was cooled to room temperature. The sample was finally washed several times 
with deionized water until the $\mathrm{pH}$ reached 7 , and was then dried for 12 hours at $105{ }^{\circ} \mathrm{C}$ overnight in an oven. This final product was called "activated carbon".

Preparation of original carbon: For comparison, carbon materials were also prepared from whey protein following the same procedure used in the preparation of the activated carbon. The difference was no nickel nitrate and potassium hydroxide. This final product is called "original carbon".

Preparation of activated carbon without Ni catalyst: Carbon materials were prepared from whey protein following the same procedures used in the preparation of the activated carbon. The difference was no nickel nitrate was introduced. This final product was called "K-activated".

Fabrication of electrodes: Electrodes were prepared by pressing the slurry of activated or original carbon (80wt\%) with acetylene black (10wt\%) and PTFE (10wt\%) on nickel foam (EQ-bcnf-16m, MTI Corporation) that had a surface area of $1 \mathrm{~cm}^{2}$. The electrodes were then dried under $60^{\circ} \mathrm{C}$ for 12 hours in an oven. Afterwards, a sandwich structure was formed by introducing two pieces of microporous polypropylene (PP) separator celgard-3501 between two electrodes, and assembling into a 2032 coin-type cell. The pressing pressure to form the coin cell was $1,000 \mathrm{~kg} \mathrm{~cm}^{-2}$.

Physical characterization: The crystalline structure of the original and activated carbon samples was investigated by X-ray diffraction (XRD) a Rigaku MiniFlex (Japan) with filtered $\mathrm{Cu}-K_{\alpha}$ radiation $(30 \mathrm{kV}, 15 \mathrm{~mA})$. Sample composition was analyzed using an SSX-100 system (Surface Science Laboratories, Inc.) equipped with a monochromated Al- $K_{\alpha}$ X-ray source, a hemispherical sector analyzer (HSA) and a resistive anode detector. For high resolution data, the lowest binding-energy $\mathrm{C}$ 1s peak was set at $285.0 \mathrm{eV}$ and used as the reference for all of the other elements. The Raman spectrum was obtained on a Horiba LABRam confocal Raman microscopean with excitation wavelength at $532 \mathrm{~nm}$ from a diode pumped solidstate laser. Physisorption analyses with $\mathrm{N}_{2}$ were carried out at $77 \mathrm{~K}$ (liquid nitrogen bath), using a Tristar 3000 Micropore analyzer. The specific surface area was determined by Brunauer -Emmett-Teller (BET) method and the pore size distribution was calculated according to the density functional theory (DFT) method using the nonlocal density functional theory (NLDFT) analysis model for 
112 carbon with slit pore model (Micromeritics Inc.). Transmission electron microscope (TEM) was 113 conducted on a JEM-2100 LaB6 STEM.

114

115

116

117

118

119

120

121

122

123

124

125

126

127

128

129

130

131

132

133

134

135

136

137

138

139

140

\section{Electrochemical characterization:}

Cyclic voltammetry (CV) and electrochemical impedance spectroscopy tests were carried on an electrochemical work station (SP-150, BioLogical, France) in $6 \mathrm{~mol} \mathrm{~L}{ }^{-1} \mathrm{KOH}$ electrolyte. The galvanostatic charge/discharge curves were measured using a BTS series battery test system (NEWARE, China).

\section{Results and discussion}

The $\mathrm{N}_{2}$ sorption-desorption isotherms of original and activated samples were shown in Fig. 1a. The BET specific surface area increased from $146 \mathrm{~m}^{2} \mathrm{~g}^{-1}$ to $2536 \mathrm{~m}^{2} \mathrm{~g}^{-1}$ after activation at $700{ }^{\circ} \mathrm{C}$. The KOH corrosion of the bio-carbon created a large number of pores that were responsible for the significant increase in the specific surface area. As shown in Fig. 1b, the pore size centered on 32 and $21 \mathrm{~nm}$ for original and activated samples, respectively, indicating most of pores belong to mesoporous. XRD patterns of the original and activated samples are shown in Fig. 2. The original sample exhibited a peak at $\sim 25^{\circ}$, corresponding to the diffraction from (002) planes of graphite according to the standard pattern for carbon [21]. On the other hand, the activated sample yielded a broad and weak (002) peak, which indicated the presence of amorphous phase. This peak showed a negative shift. Furthermore, the activated sample showed a diffraction peak at $43.5^{\circ}[22]$, corresponding to (101) plane. These results clearly indicated that significant changes in the crystal structure and the grain size occurred after activation. The observed changes were attributed to the high-density pores in the activated sample.

To further understand the activation effect observed in BET and XRD analysis, TEM studies of both original and activated samples were performed (Fig. 3). The original sample had some degree of graphitization without any porous structure (Fig. 3a and b). On the other hand, the activated sample exhibited a complete different morphology, with a high number of interconnected cavities developed from preferential etching by $\mathrm{KOH}$ in the amorphous portions of the carbon as displayed in Fig. 3c and d [23]. These results were in good agreement with the data of XRD and nitrogen adsorption analysis. The pores could serve as reservoirs for electrolyte, and therefore shorten the diffusion distance from the external electrolyte to the interior surfaces 
141 of electrode materials [24]. The distinct pore structures were further confirmed using 142 tomography to reconstruct the 3-D structure (see attached supporting information, which is a movie showing the full range pore structures. In addition, selected area electron diffraction

144 (SAED) was used to study the degree of crystallinity. The original sample showed faint light 145 rings caused by a mixture of crystalline and amorphous phases, while the activated sample showed a well-defined dot matrix, indicating good crystallinity with very small crystals.

147 The structural difference between the original and activated samples was also confirmed by 148 Raman spectroscopy. As shown in Fig. 4a, the featured $D$-band and $G$-band peaks were displayed in both samples. The $D$-band located at $1340 \mathrm{~cm}^{-1}$ was attributed to the disordered graphite with $A_{l g}$ symmetry. The $G$-band centered at $1580 \mathrm{~cm}^{-1}$ corresponded to the first-order scattering of the $E_{2 g}$ mode of $s p^{2}$ carbon domains [25]. Meanwhile, the ratio of intensity between $D$-band and G-band $\left(I_{D} / I_{G}\right)$ represented the degree of graphitization, a lower value means the higher degree of graphitization [25]. The $I_{D} / I_{G}$ values for the original and activated samples were 0.85 , and 0.83 , respectively, suggesting that there was higher degree of graphitization in the activated sample. This was likely due to the contribution of $\mathrm{Ni}\left(\mathrm{NO}_{3}\right)_{2}$ which acted to catalyze graphitization in the pyrolsis process [26, 27].

To clarify the effects of $\mathrm{Ni}$ on the chemical state of $\mathrm{N}$ in the original and activated samples, $\mathrm{X}$ ray photoelectron spectroscopy (XPS) measurement (Fig. 4b, c and d) were performed. As shown in Fig. 4b, the full range XPS survey spectra of both samples contained signals from C, N and $\mathrm{O}$, indicating the ingredient of the two samples. Based on the XPS analysis, the atomic content of $\mathrm{C}, \mathrm{N}$ and $\mathrm{O}$ for activated and original sample was 82.8, 7.04, 8.67 and 88.7, 3.5, 7.8, respectively. Since XPS technique was surface analysis, further elemental analysis was performed to evaluate the buck content of $\mathrm{N}$. The results showed that the content of $\mathrm{N}$ for the activated sample was $0.41 \%$, which was lower than that of original sample $(2.68 \%)$. The bonding configurations of the carbon and nitrogen were characterized by high resolution $\mathrm{C} 1 \mathrm{~s}$ and $\mathrm{N} 1 \mathrm{~s}$ spectra (Fig 4c and d). For the $\mathrm{C}$ 1s spectrum, three characteristic peaks at approximately $285 \mathrm{eV}$, $285.9 \mathrm{eV}$ and $288 \mathrm{eV}$ were observed and, were assigned to $\mathrm{C}-\mathrm{C}, \mathrm{C}-\mathrm{N}$ and $\mathrm{C}=\mathrm{O}$ bonds, respectively [28]. For N 1s spectrum, $\mathrm{N}$ species in activated sample were pretty different from that in the original sample. The high resolution $\mathrm{N}$ 1s spectrum of the original sample could be deconvoluted into three peaks, including pyridinic-N ( 398.7 eV), quantum-N ( 400.9 eV), and 
171 N-oxides of pyridine-N ( 403.8 eV) [29, 30]. However, only two types of $\mathrm{N}$ (pyridinic-N, 172 quantum-N) were observed in the activated carbon samples, implying that the N-oxides of 173 pyridine- $\mathrm{N}$ was either lost with the removal of $\mathrm{Ni}$ by $\mathrm{HCl}$ washing or transformed into quantum$174 \mathrm{~N}$ and pyridine-N. As it has been proved that transition metals Fe and Co could form FeN $\mathrm{N}_{\mathrm{x}}$ and $175 \mathrm{CoN}_{\mathrm{x}}[31,32]$ composite during the process of plyolysis under the introduction of N-containing 176 substance rather than $\mathrm{Ni}$. On the other hand, $\mathrm{Ni}\left(\mathrm{NO}_{3}\right)_{2}$ decomposed into $\mathrm{Ni}$ oxides that was subsequently reduced into metallic Ni by amorporous $\mathrm{C}$ at elevated temperatures $[33,34]$. Due to random diffusion effect [35], C-Ni interaction [36], mutual action between Ni nanoparticles [37], external forces (e.g. gravity) or a combined role of multiple factors, the $\mathrm{Ni}$ nanoparticles deposited on the surface of carbon tended to move in the surface carbon matrix, modifying the amorphous carbon to produce quasi-graphitic nanostructures according to "dissolutionprecipitation" mechanism. Meanwhile, unsaturated dangling bonds located at the edge of nascent carbon nanostructures resulted in the formation of an integrated carbon structure. The contribution of $\mathrm{Ni}$ in graphitization was likely that the N-oxides of pyridine- $\mathrm{N}$ was transformed into quantum-N, also named as graphitic-N. This tranformation was expected to enhance the performance of EDLC, because a report indicated that the pyridine-N configurations induced pseudocapacitance enhancement while the quantum-N configuration improved the conductivity of carbon materials [30].

The electrochemical properties of the original and activated samples were measured in 6 mol L $\mathrm{KOH}$ electrolyte with a two-electrode cell system at room temperature using a SP-150 BioLogical electrochemical work station. Fig. 5a, c and e showed the CV measurement results of the original, activated and K-activated electrodes at various scanning rates ranging from 10 to $200 \mathrm{mV} \mathrm{s}^{-1}$. The CV curve of the activated electrode exhibited a typical rectangular shape at all scanning rates in contrast to that of the original. These results implied that, due to the contribution of Ni catalytic graphitization, the activated electrode possessed a better capacitive performance and electrical conductivity than that of the original electrode.

The specific capacitance of the original and activated electrodes was calculated by the following equation [16]:

$$
C=\frac{2 I \Delta t}{m \Delta v}
$$


where $\mathrm{C}, I, \Delta t, m, \Delta v$ are the specific capacitance, the charge/discharge current, the corresponding charge or discharge time, the mass of active materials on single electrode, and the total corresponding potential change, respectively. As shown in Fig. 5a, c and e, the activated electrode had specific capacitance of $200-248 \mathrm{~F} \mathrm{~g}^{-1}$ from $10 \mathrm{mV} \mathrm{s}^{-1}$ to $200 \mathrm{mV} \mathrm{s}^{-1}$, which is pretty better than that of $\mathrm{K}$-activated $\left(153-168 \mathrm{~F} \mathrm{~g}^{-1}\right)$ and original electrode $\left(20-44 \mathrm{~F} \mathrm{~g}^{-1}\right)$. In addition, compared with other carbon based electrode materials, such as hierarchical porous carbon (294 $\mathrm{F} \mathrm{g}^{-1}$ ) [38], N-doped porous carbon (245 $\mathrm{F} \mathrm{g}^{-1}$ ) [39], N-Doped ordered mesoporous carbon $\left(227 \mathrm{~F} \mathrm{~g}^{-1}\right)$ [40], and N-modified few-layer graphene $227\left(\mathrm{~F} \mathrm{~g}^{-1}\right)$ [41], the prepared activated electrode materials exhibited comparable or even better performance at similar measurement condition for symmetric supercapacitors.

The galvanostatic charge/discharge curves of original and activated electrodes at different current densities of 0.5, 1.0, 2.0 and $5.0 \mathrm{~A} \mathrm{~g}^{-1}$ were shown in Fig. 5b, $\mathrm{d}$ and $\mathrm{f}$, respectively. For the activated electrode, the shape of the curves was almost typical isosceles triangular and highly linear, indicating that the electrode material had ideal capacitive characteristics and excellent electrochemical reversibility. In contrast, the charge/discharge performance of the K-activated and original electrodes deteriorated sharply at increased current density.

Fig. 6a showed the electrochemical impedance spectroscopy results measured in the range from 0.1 to $100 \mathrm{kHz}$ in the two-electrode cell. The $x$-intercept donated as equivalent series resistance (ESR) $R_{s}$, a semicircle and a $45^{\circ}$ phase shift line appeared at the high and low frequency region, respectively. Typically, the resistance consisted of bulk electrolyte resistance, interfacial resistance and apparent resistance of intra-particle pores; the first two terms were associated with the electrolyte and the last term was associated with both the electrolyte and electrode materials [42]. The activated electrode displayed slightly larger $R_{s}$ value ( $0.55 \Omega$ vs 0.34 and $0.13 \Omega$ for original and K-activated electrodes, respectively), but smaller semicircle at the high frequency region and a more s line at the low frequency region than that of original and $\mathrm{K}$-activated electrodes, suggesting the activated electrode generally had better conductivity than original and K-activated electrodes. These results were attributed to i) the pores serving as ion-buffering reservoirs that shortened the ion diffusion distance from the external electrolyte to the interior surfaces; ii) the thinner walls of carbon framework enhanced the diffusivity of the ions in the pores $[21,24]$. 
The long-term stability of the EDLC was verified through cycle-life tests, which were conducted in $6 \mathrm{~mol} \mathrm{~L}^{-1} \mathrm{KOH}$ electrolyte at different current densities ranging from 0.1 to $5 \mathrm{~A} \mathrm{~g}^{-1}$. As shown in Fig. 6b, after 4,000 cycles at different current densities, the activated electrode retained $84 \%$ of its specific capacitance upon increasing the current density from $0.1 \mathrm{~A} \mathrm{~g}^{-1}$ to $5 \mathrm{~A} \mathrm{~g} \mathrm{~g}^{-1}$, which behaved much better than original and K-activated electrodes. Within 1,000 cycles at different current densities, the activated electrode did not exhibited capacitance loss and the specific capacitance was much larger than that of original and K-activated electrode. The high specific capacitance and good stability were due to the enhanced conductivity and large amount of interconnected pores, as verified by the TEM characterization.

To demonstrate the operational characteristics, the energy and power densities were calculated according to the following equations [38]:

$$
\begin{aligned}
E & =\frac{1}{2} C(\Delta \mathrm{V})^{2} \\
P & =\frac{E}{t}
\end{aligned}
$$

where $E$ is the average energy density $\left(\mathrm{Wh} \mathrm{kg}^{-1}\right), C$ is the specific capacitance of the symmetric supercapacitor, $\Delta \mathrm{V}$ is the voltage range, $P$ is the average power density $\left(\mathrm{W} \mathrm{kg}^{-1}\right)$ and $t$ is the discharge time, respectively. Ragone plots of the original, K-activated and activated electrodes was shown on Fig. 7. The energy density of the activated electrode reached $12.4 \mathrm{Wh} \mathrm{kg}^{-1}$ at a power density of $495 \mathrm{~W} \mathrm{~kg}^{-1}$ and still remained $10.6 \mathrm{Wh} \mathrm{kg}^{-1}$ at a power density of $8.5 \mathrm{~kW} \mathrm{~kg}^{-1}$, which was higher than that of original $\left(6.1 \mathrm{Wh} \mathrm{kg}^{-1}\right.$ at $600 \mathrm{~W} \mathrm{~kg}^{-1}$ and $2.65 \mathrm{Wh} \mathrm{kg}^{-1}$ at $5.2 \mathrm{~kW}$ $\mathrm{kg}^{-1}$ ) and $\mathrm{K}$-activated $\left(10.5 \mathrm{Wh} \mathrm{kg}^{-1}\right.$ at $420.8 \mathrm{~W} \mathrm{~kg}^{-1}$ and $10.5 \mathrm{Wh} \mathrm{kg}^{-1}$ at $8.1 \mathrm{~kW} \mathrm{~kg}^{-1}$ ) electrodes. The above results indicated that $\mathrm{Ni}$ catalytic graphitization greatly boosted the electrochemical performance and EDLCs devices with excellent electrochemical stability and cyclability could be obtained using the activated carbon electrode.

\section{Conclusion}

In summary, high performance EDLC electrode materials were derived from whey protein by the combination of efficient $\mathrm{KOH}$ activation and $\mathrm{Ni}$ catalytic graphitization during pyrolysis. The prepared carbon electrodes had high specific surface area, high porosity, and $\mathrm{N}$ doping. These 
257 characteristics led to efficient diffusion of charges and increased electrical conductivity, which

258 contributed to large specific capacitance of 248, 227, 217 and $210 \mathrm{~F} \mathrm{~g}^{-1}$ at current densities of 0.1 ,

$2590.5,1.0$, and 5.0 $\mathrm{A} \mathrm{g}^{-1}$, respectively. Furthermore, the activated electrodes possessed excellent

260 cyclic stability with specific capacitance retention of $\sim 100 \%$ after 1,000 charge/discharge cycles

261 at each current density. Moreover, higher energy density of $12.4 \mathrm{Wh} \mathrm{kg}^{-1}$ was achieved at a

262 power density of $495 \mathrm{~W} \mathrm{~kg}^{-1}$ for the prepared electrodes. These results confirmed that the whey-

263 protein-based activated electrode is a potential candidate for high performance EDLCs.

264 Acknowledgement

265 This research was funded by following projects: i) "Development of high value carbon based 266 adsorbents from thermochemically produced biochar" 2011-67009-20030 USDA-NIFA 267 Agriculture and Food Research Initiative Sustainable Bioenergy Program, which funded 268 micropore analyzer, electrochemical analyzer and instruments for preparing carbon materials. ii) 269 NSF EPSCoR Track II Dakota BioCon Center, which supported Mr. Keliang Wang for his PhD 270 study and XPS analysis of carbon samples. iii) The Characterization Facility, University of 271 Minnesota, which received partial support from NSF through the MRSEC program and iv) 272 National Science Foundation grant CMMI-1462389.

\section{References}

274 [1] Kühne R. Electric buses-An energy efficient urban transportation means. Energy $2752010 ; 35(12): 4510-3$.

276 [2] Yan J, Wang Q, Wei T, Fan Z. Recent advances in design and fabrication of electrochemical 277 supercapacitors with high energy densities. Adv Energ Mater 2014;4:1-43.

278 [3] Inamdar A, Jo Y, Kim J, Han J, Pawar S, Kalubarme R, et al. Synthesis and enhanced 279 electrochemical supercapacitive properties of manganese oxide nanoflake electrodes. Energy $280 \quad 2015 ; 83: 532-8$.

281 [4] Lee JW, Ahn T, Kim JH, Ko JM, Kim J-D. Nanosheets based mesoporous NiO 282 microspherical structures via facile and template-free method for high performance 283 supercapacitors. Electrochim Acta 2011;56:4849-4857. 
284 [5] Deng W, Lan W, Sun Y, Su Q, Xie E. Porous CoO nanostructures grown on three-dimension 285 graphene foams for supercapacitors electrodes. Appl Surf Sci 2014;305:433-438.

286 [6] Kim J, Ju H, Inamdar AI, Jo Y, Han J, Kim H, et al. Synthesis and enhanced electrochemical 287 supercapacitor properties of $\mathrm{Ag}-\mathrm{MnO}_{2}$-polyaniline nanocomposite electrodes. Energy $288 \quad 2014 ; 70: 473-7$.

289 [7] Candelaria SL, Garcia BB, Liu D, Cao G. Nitrogen modification of highly porous carbon for 290 improved supercapacitor performance. J Mater Chem Mater 2012;22:9884-9889.

291 [8] Chen XY, Chen C, Zhang ZJ, Xie DH, Deng X, Liu JW. Nitrogen-doped porous carbon for 292 supercapacitor with long-term electrochemical stability. J Power Sources 2013;230:50-58.

293 [9] Chen XY, Xie DH, Chen C, Liu JW. High-performance supercapacitor based on nitrogen294 doped porous carbon derived from zinc (II)-bis (8-hydroxyquinoline) coordination polymer. J 295 Colloid Interface Sci 2013;393:241-248.

296 [10] Cheng Q, Tang J, Ma J, Zhang H, Shinya N, Qin L-C. Graphene and carbon nanotube 297 composite electrodes for supercapacitors with ultra-high energy density. Phy. Chem Chem Phys $298 \quad 2011 ; 13: 17615-17624$.

299 [11] Gong K, Du F, Xia Z, Durstock M, Dai L. Nitrogen-doped carbon nanotube arrays with 300 high electrocatalytic activity for oxygen reduction. Science 2009;323:760-764.

301 [12] Kim J-H, Sharma AK, Lee Y-S. Synthesis of polypyrrole and carbon nano-fiber composite 302 for the electrode of electrochemical capacitors. Mater Lett 2006;60:1697-1701.

303 [13] Khalid B, Meng Q, Li J, Cao B. Nitrogen rich graphene-cross-linked melamine 304 formaldehyde carbon cryogels for supercapacitors. Electrochim Acta 2014;142:101-107.

305 [14] Wang K, Li L, Zhang T, Liu Z. Nitrogen-doped graphene for supercapacitor with long-term 306 electrochemical stability. Energy 2014;70:612-7. 
307 [15] Shao Z, Li H, Li M, Li C, Qu C, Yang B. Fabrication of polyaniline nanowire/TiO 2 308 nanotube array electrode for supercapacitors. Energy. 2015. 87:578-585.

309 [16] Wahid M, Parte G, Phase D, Ogale S. Yogurt: a novel precursor for heavily nitrogen doped 310 supercapacitor carbon. J Mater Chem Mater A 2015;3:1208-1215.

311 [17] Sun L, Tian C, Li M, Meng X, Wang L, Wang R, et al. From coconut shell to porous 312 graphene-like nanosheets for high-power supercapacitors. J Mater Chem Mater A 2013;1:64623136470.

314 [18] Jiménez-Cordero D, Heras F, Gilarranz MA, Raymundo-Piñero E. Grape seed carbons for 315 studying the influence of texture on supercapacitor behaviour in aqueous electrolytes. Carbon $316 \quad 2014 ; 71: 127-138$.

317 [19] Jin H, Wang X, Gu Z, Anderson G, Muthukumarappan K. Distillers dried grains with 318 soluble (DDGS) bio-char based activated carbon for supercapacitors with organic electrolyte 319 tetraethylammonium tetrafluoroborate. J Environ Chem Eng 2014;2:1404-1409.

320 [20] Seo DH, Yick S, Han ZJ, Fang JH, Ostrikov KK. Synergistic fusion of vertical graphene 321 nanosheets and carbon nanotubes for high-performance supercapacitor electrodes. 322 ChemSusChem 2014;7:2317-2324.

323 [21] Ning X, Zhong W, Li S, Wang Y, Yang W. High performance nitrogen-doped porous 324 graphene/carbon frameworks for supercapacitors. J Mater Chem Mater A 2014;2:8859-8867.

325 [22] Fan Y, Yang X, Zhu B, Liu P-F, Lu H-T. Micro-mesoporous carbon spheres derived from 326 carrageenan as electrode material for supercapacitors. J Power Sources 2014;268:584-590.

327 [23] Cheng K-K, Hsu T-C, Kao L-H. A microscopic view of chemically activated amorphous 328 carbon nanofibers prepared from core/sheath melt-spinning of phenol formaldehyde-based 329 polymer blends. J. Mater Sci 2011;46:3914-3922. 
330 [24] Wang DW, Li F, Liu M, Lu GQ, Cheng HM. 3D aperiodic hierarchical porous graphitic 331 carbon material for high-rate electrochemical capacitive energy storage. Angew Chem Int Ed. $332 \quad 2008 ; 47: 373-376$.

333 [25] J. Qi, L. Jiang, S. Wang, G. Sun, Synthesis of graphitic mesoporous carbons with high 334 surface areas and their applications in direct methanol fuel cells. Appl Catal B 2011;107:95-103. 335 [26] Rodríguez-Manzo JA, Pham-Huu C, Banhart F. Graphene growth by a metal-catalyzed 336 solid-state transformation of amorphous carbon. ACS nano 2011;5:1529-1534.

337 [27] Choi CH, Park SH, Woo SI. N-doped carbon prepared by pyrolysis of dicyandiamide with 338 various $\mathrm{MeCl}_{2} \cdot \mathrm{xH}_{2} \mathrm{O}(\mathrm{Me}=\mathrm{Co}, \mathrm{Fe}$, and $\mathrm{Ni})$ composites: effect of type and amount of metal seed 339 on oxygen reduction reactions. Appl Catal B 2012;119:123-131.

340 [28] Ruan C, Ai K, Lu L. Biomass-derived carbon materials for high-performance supercapacitor 341 electrodes. RSC Adv 2014;4:30887-30895.

342 [29] Sevilla M, Yu L, Zhao L, Ania CO, Titiricic M-M. Surface modification of CNTs with N343 doped carbon: an effective way of enhancing their performance in supercapacitors. ACS Sustain 344 Chem Eng 2014;2:1049-1055.

345 [30] Lee W-h, Moon JH. Monodispersed N-doped carbon nanospheres for supercapacitor 346 application. ACS Appl Mater Inter 2014;6:13968-13976.

347 [31] Wang Y-s, Zhang B-w, Li Y-f, Liu D-j, He X-q, Si Z-j. Nitrogen-doped graphene-supported $348 \mathrm{Co} / \mathrm{CoN}_{\mathrm{x}}$ nanohybrid as a highly efficient electrocatalyst for oxygen reduction reaction in an 349 alkaline medium. RSC Adv 2014;4:62272-62280.

350 [32] Kong A, Zhu X, Han Z, Yu Y, Zhang Y, Dong B, et al. Ordered hierarchically micro-and 351 mesoporous $\mathrm{Fe}-\mathrm{N}_{\mathrm{x}}$-embedded graphitic architectures as efficient electrocatalysts for oxygen 352 reduction reaction. ACS Catal 2014;4:1793-1800. 
353 [33] Brockner W, Ehrhardt C, Gjikaj M. Thermal decomposition of nickel nitrate hexahydrate, $354 \mathrm{Ni}\left(\mathrm{NO}_{3}\right)_{2} \cdot 6 \mathrm{H}_{2} \mathrm{O}$, in comparison to $\mathrm{Co}\left(\mathrm{NO}_{3}\right)_{2} \cdot 6 \mathrm{H}_{2} \mathrm{O}$ and $\mathrm{Ca}\left(\mathrm{NO}_{3}\right)_{2} \cdot 4 \mathrm{H}_{2} \mathrm{O}$. Thermochim Acta $355 \quad 2007 ; 456: 64-68$.

356 [34] Sevilla M, Fuertes A. Graphitic carbon nanostructures from cellulose. Chem Phys Lett $357 \quad 2010 ; 490: 63-68$.

358 [35] Davis SC, Klabunde KJ. Unsupported small metal particles: preparation, reactivity, and 359 characterization. Chem Rev 1982;82:153-208.

360 [36] Anton R. On the reaction kinetics of Ni with amorphous carbon. Carbon 2008:656-662.

361 [37] Nagaev ÉL. Small metal particles. Physics-Usp 1992;35:747-782.

362 [38] Wang Q, Yan J, Wang Y, Wei T, Zhang M, Jing X, et al. Three-dimensional flower-like and 363 hierarchical porous carbon materials as high-rate performance electrodes for supercapacitors. 364 Carbon. 2014;67:119-27.

365 [39] Xu B, Zheng D, Jia M, Cao G, Yang Y. Nitrogen-doped porous carbon simply prepared by 366 pyrolyzing a nitrogen-containing organic salt for supercapacitors. Electrochim Acta $367 \quad 2013 ; 98: 176-8$

368 [40] Wei J, Zhou D, Sun Z, Deng Y, Xia Y, Zhao D. A controllable synthesis of rich nitrogen 369 doped ordered mesoporous carbon for $\mathrm{CO}_{2}$ capture and supercapacitors. Adv Fun Mater $370 \quad 2013 ; 23: 2322-8.2$.

371 [41] Xiao N, Lau D, Shi W, Zhu J, Dong X, Hng HH, et al. A simple process to prepare 372 nitrogen-modified few-layer graphene for a supercapacitor electrode. Carbon 2013;57:184-90.

373 [42] Yoo HD, Jang JH, Ryu JH, Park Y, Oh SM. Impedance analysis of porous carbon electrodes 374 to predict rate capability of electric double-layer capacitors. J Power Sources 2014;267:411-420. 
Fig. 1
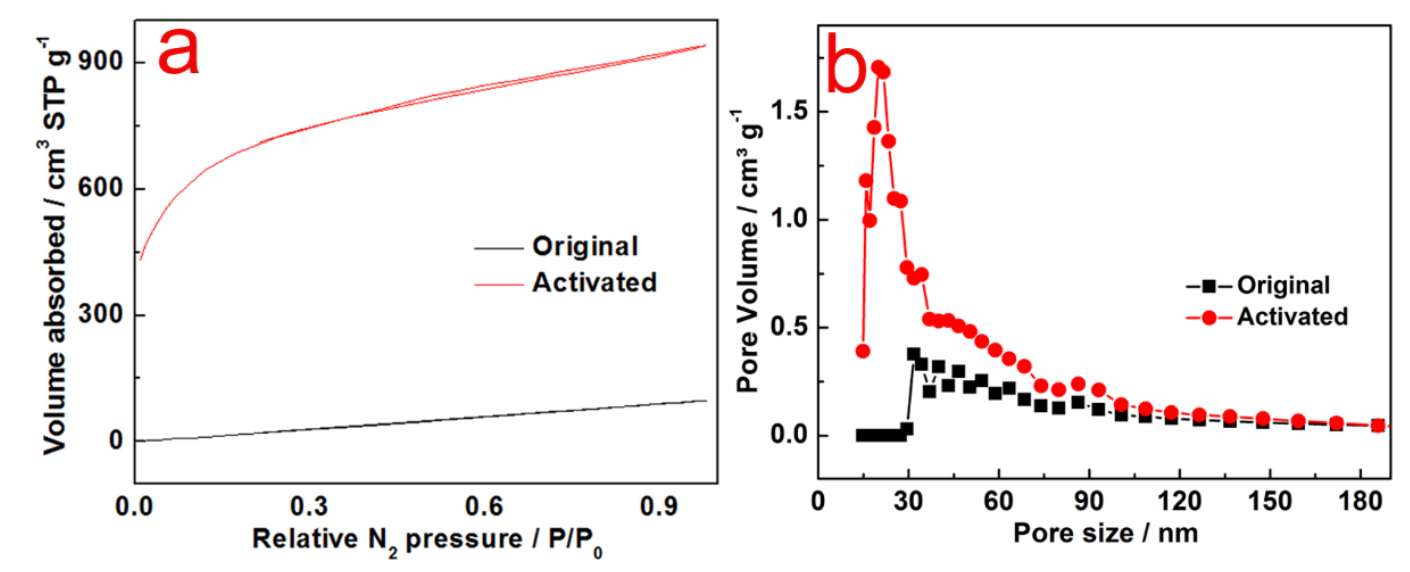
Fig. 2

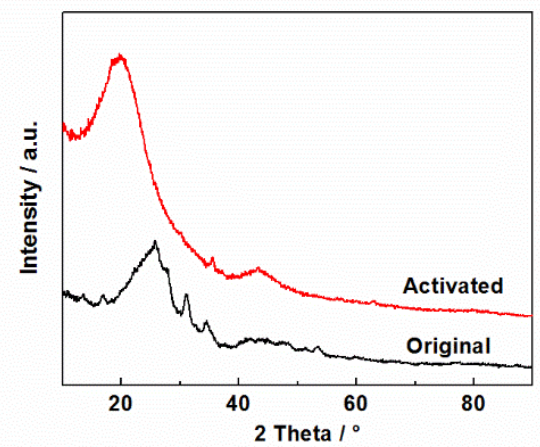


Fig. 3

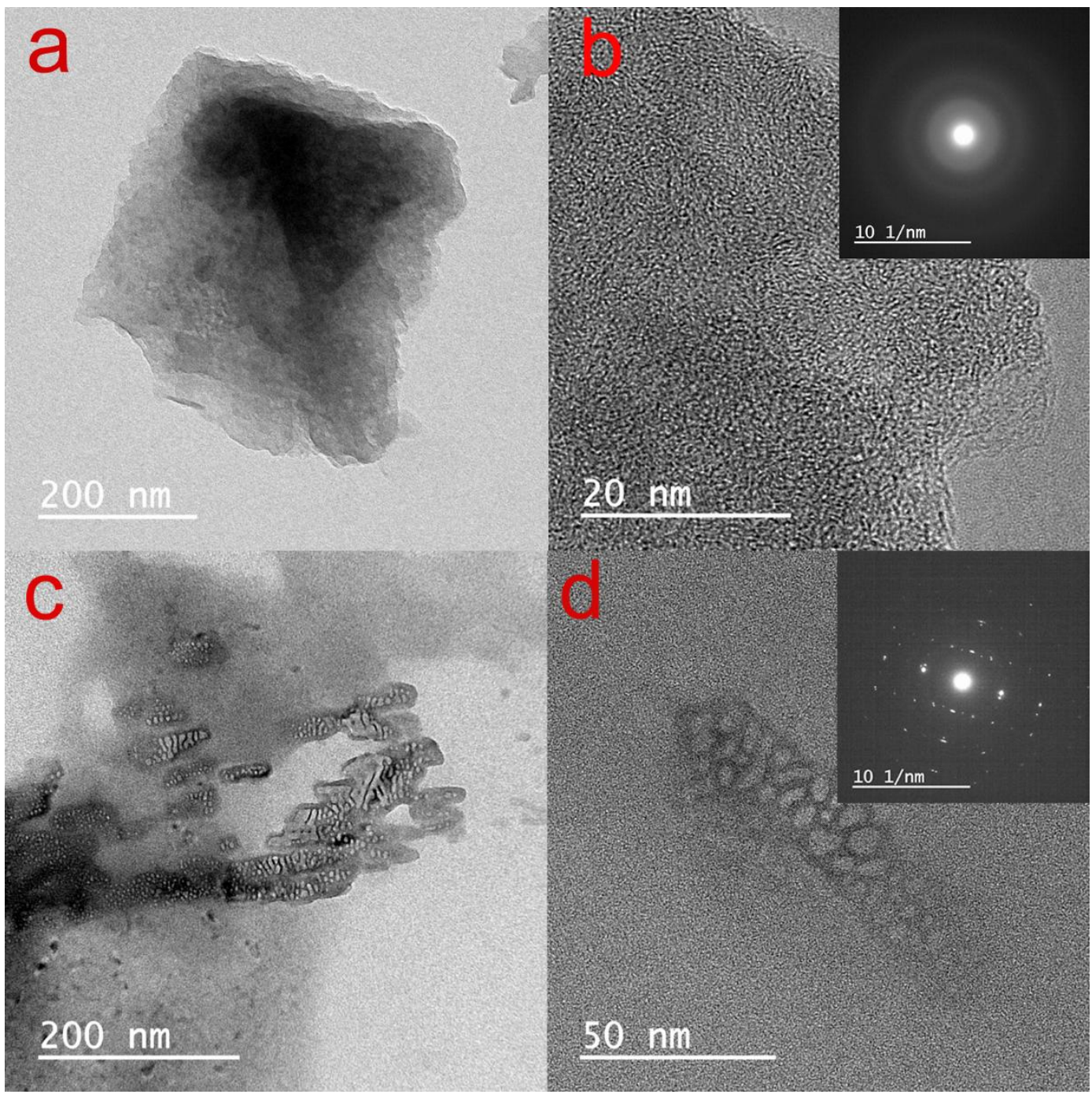


Fig. 4
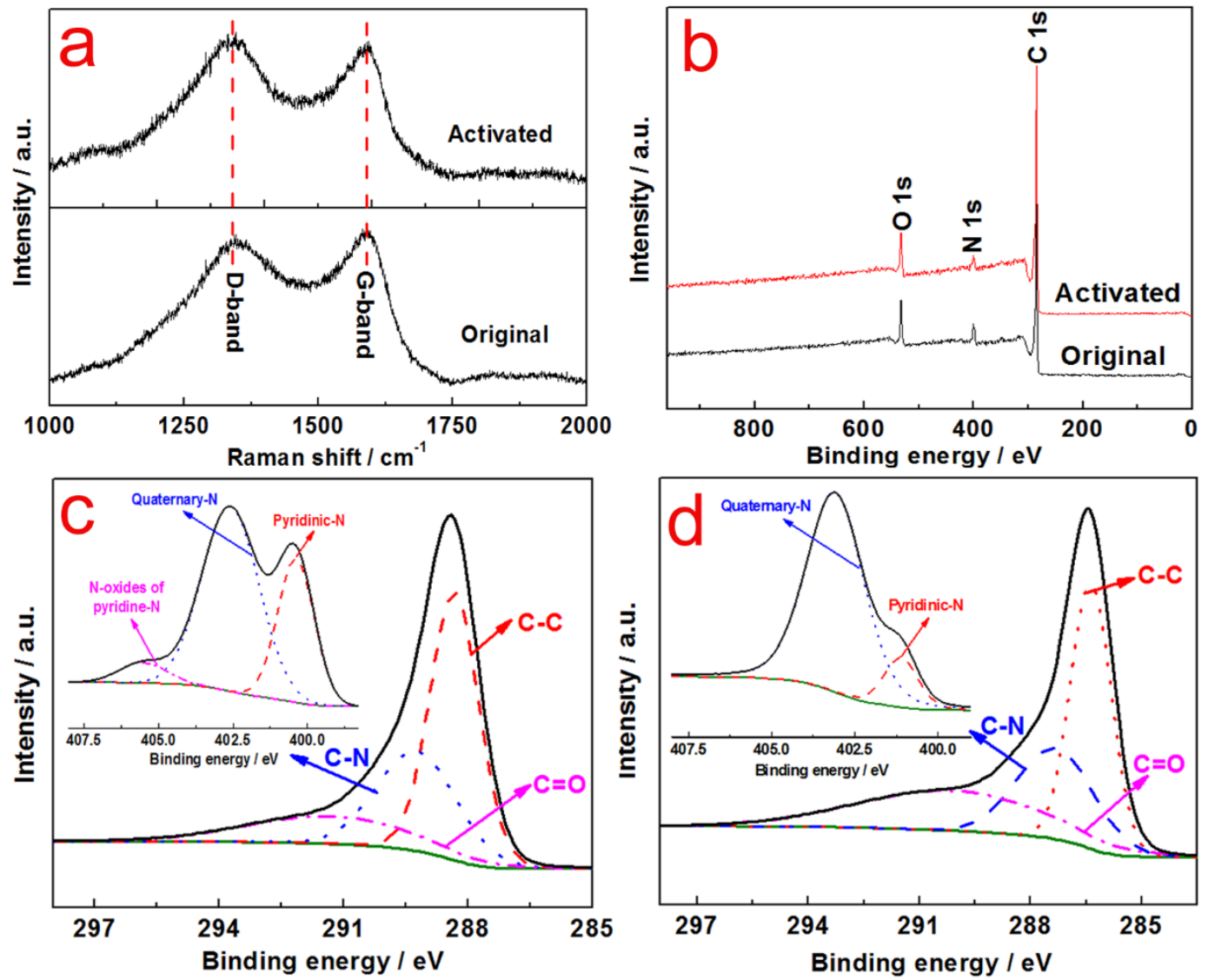
Fig. 5
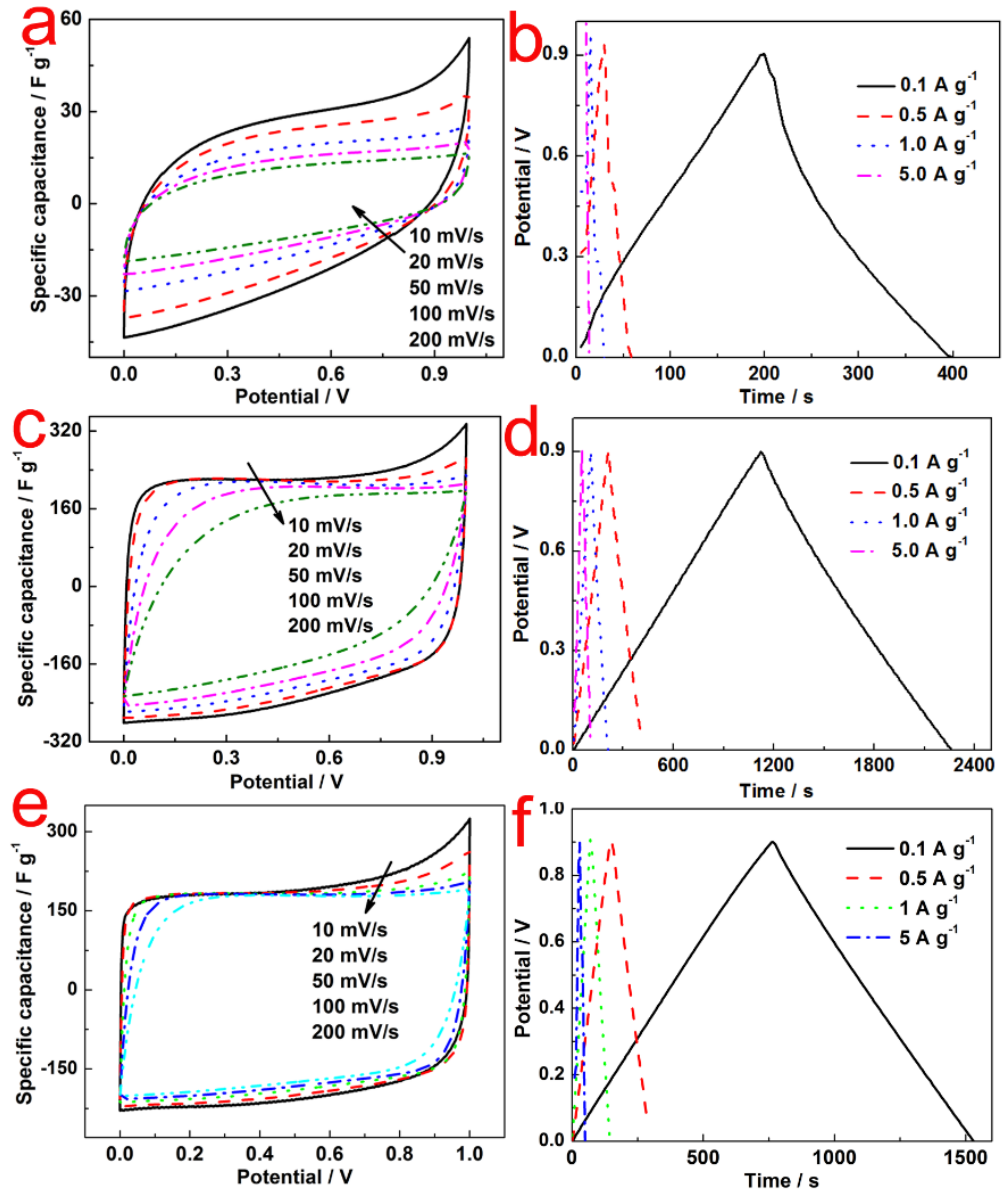
Fig. 6
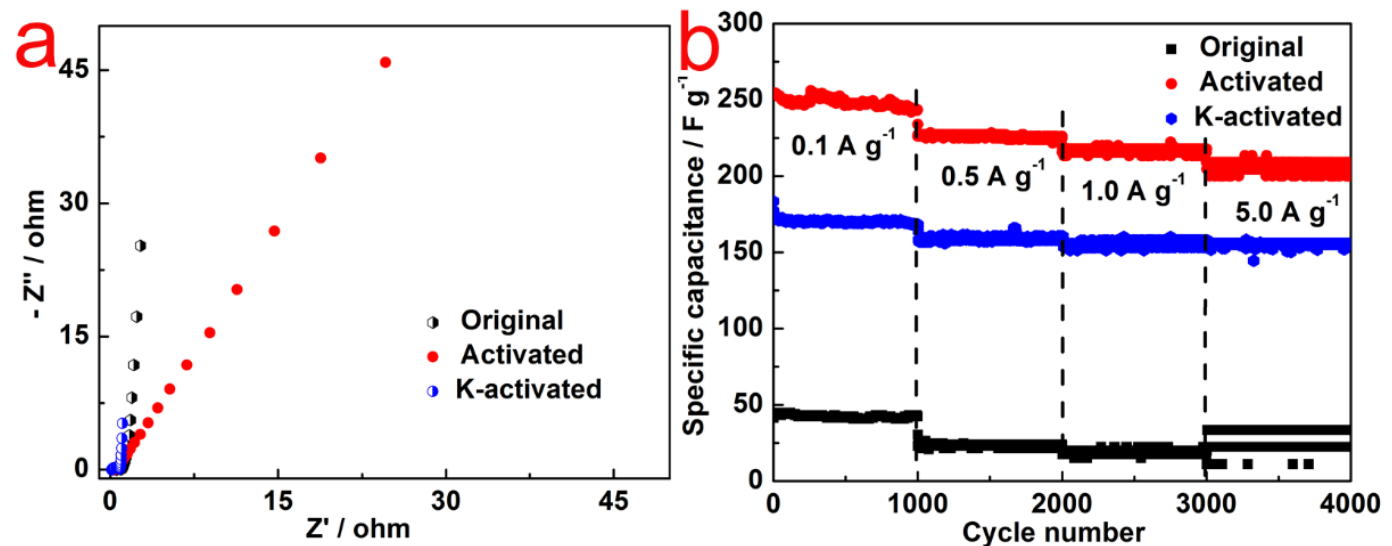
Fig. 7

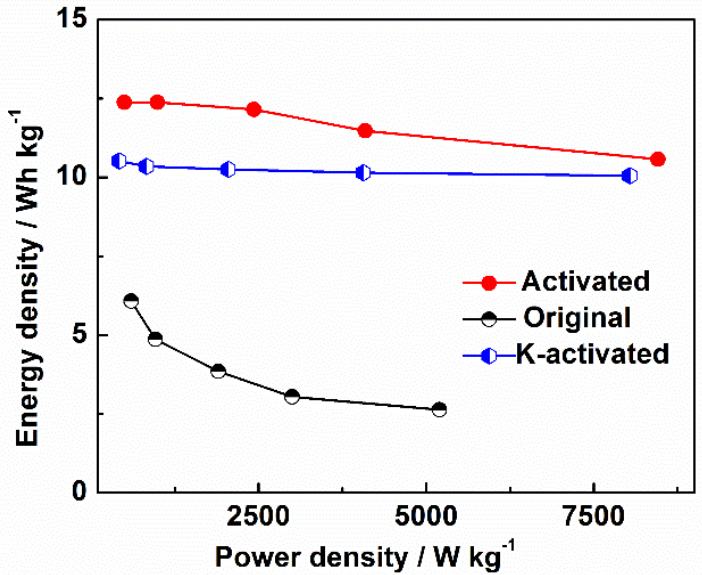


Fig. $1 \mathrm{~N}_{2}$ sorption-desorption isotherms (a) and pore size distribution (b).

Fig. 2 Wide-angle XRD pattern for original and activated sample.

Fig. 3 Different magnifications TEM images of original (a, b) and activated (c, d). Inset in (b) and (d) shows SAED for original and activated, respectively.

Fig. 4 Raman spectra of original and activated (a); XPS survey spectra (b) of original and activated. C 1s XPS spectra of original (c) and activated (d); Inset in (c) and (d) shows N1s XPS spectra of original and activated, respectively.

Fig. 5 CV curves of (a) original, (c) activated and (e) K-activated electrodes at various scanning rates ranging from 10 to $200 \mathrm{mV} \mathrm{s}^{-1}$; Galvanostatic charge/discharge curves of (b) original, (d) activated and (f) K-activated electrodes at different current density ranging from 0.1 to $5 \mathrm{~A} \mathrm{~g}^{-1}$.

Fig. 6 Nyquist plots of (a) original activated and K-activated electrodes; (b) Cycle life of original activated and $\mathrm{K}$-activated electrodes in $6 \mathrm{~mol} \mathrm{~L}^{-1} \mathrm{KOH}$ electrolyte at different current density ranging from 0.1 to $5 \mathrm{~A} \mathrm{~g}^{-1}$.

Fig. 7 Ragone plots of the original, K-activated and activated electrodes. 


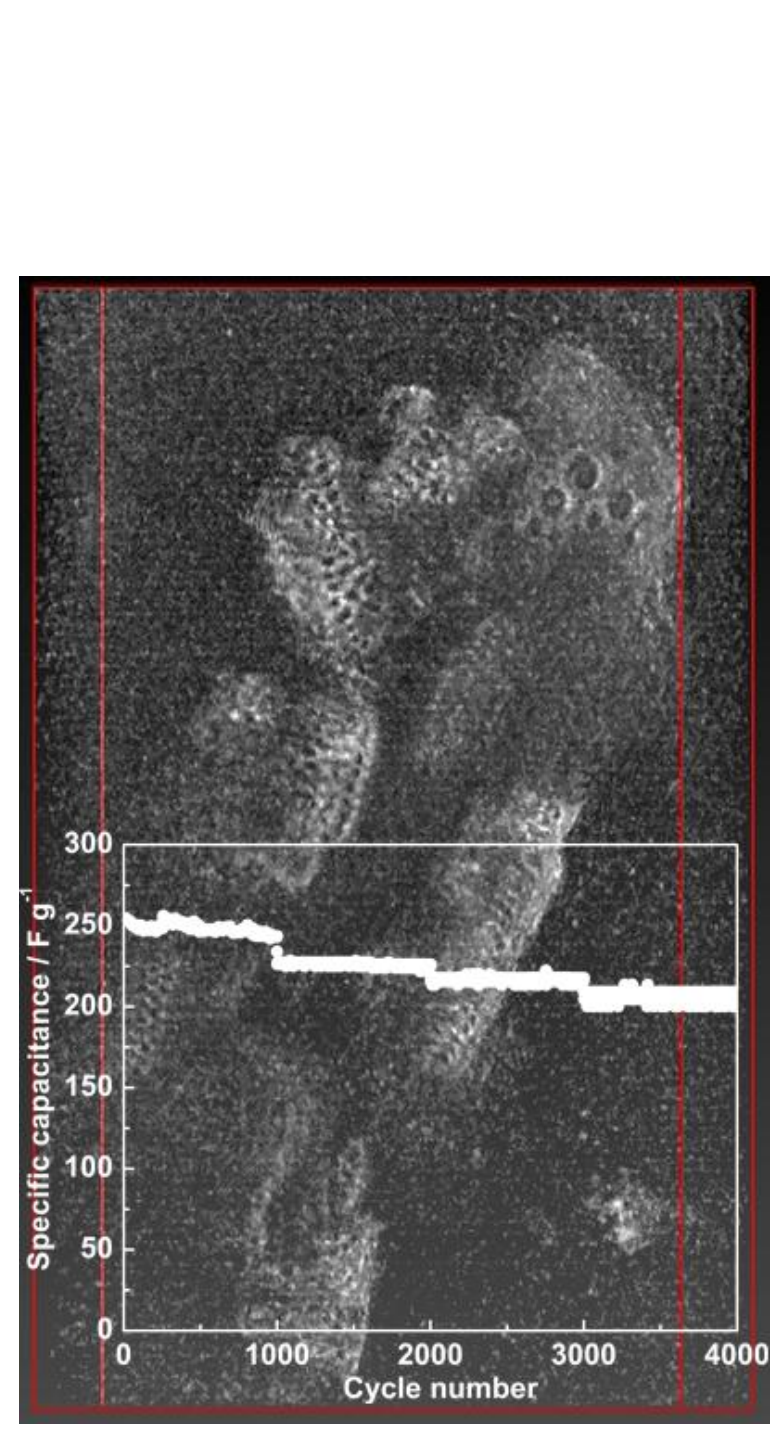

Figure

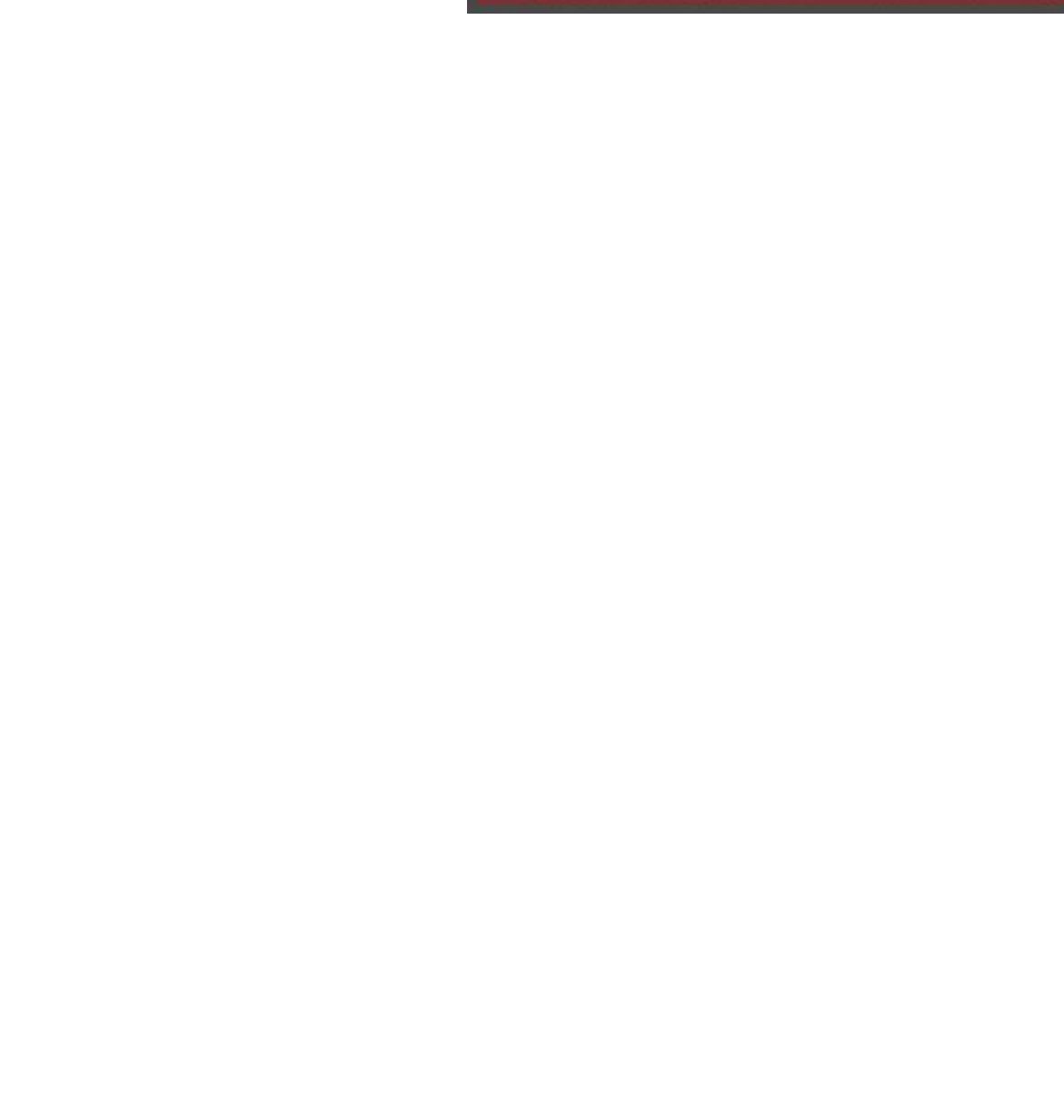
.

.

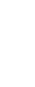

